\title{
PESTES Y PANDEMIAS EN LAANTIGÜEDAD. VISIONES CLÁSICAS E INTERPRETACIONES MODERNAS DE LAS EPIDEMIAS GRECORROMANAS
}

Javier Espino Martín*

RESUMEN: Pestes y pandemias están de actualidad por la crisis de covid-19. Aunque nuestro mundo no está acostumbrado a las epidemias, han sido muy frecuentes a lo largo de la historia de la humanidad. En el presente estudio se ofrece un análisis de distintas pestes que asolaron el mundo grecorromano, con las explicaciones que les dieron los autores clásicos y las crisis sociopolíticas que supusieron, muy similares a la actual.

rose

PESTS AND PANDEMICS IN ANTIQUITY. CLASSICAL VIEWS AND MODERN INTERPRETATIONS OF GRECO-ROMAN EPIDEMICS

ABSTRACT: Pests and pandemics are in the news because of the covid-19 crisis. Although our world is not accustomed to epidemics, they have been very frequent throughout human history. This paper offers an analysis of the different plagues that devastated the Greco-Roman world, with the discussions made by classical authors and the political-social crises that they supposed, very similar to the present one.

PALABRAS CLAVE: corpúsculos infecciosos, epidemia, humores, miasmas.

KEY WORDS: epidemic, humors, infectious corpuscles, miasmas.

RECEPCIÓN: 22 de septiembre de 2020.

APROBACIÓN: 13 de octubre de 2020.

DOI: $10.5347 / 01856383.0135 .000299472$

* Departamento Académico de Estudios Generales, ITAM. 
Se prohíbe su reproducción total o parcial por cualquier medio, incluido electrónico, sin permiso previo y por escrito de los editores. 


\section{PESTES Y PANDEMIAS \\ EN LA ANTIGÜEDAD. \\ VISIONES CLÁSICAS \\ E INTERPRETACIONES \\ MODERNAS DE \\ LAS EPIDEMIAS \\ GRECORROMANAS}

\section{Etimología y panorama histórico de la peste en la Antigüedad clásica}

\section{El término "peste" procede de latín}

pestis, -is, que viene de la raíz verbal perdere (per y dare, en español ha dado "perder", con el sentido de "entregar completamente" [se entiende que la vida o el aliento vital]). La peste, por lo tanto, tiene un sentido originario de "perdición”, o "destrucción” y, por extensión, de aniquilación de una civilización o de un pueblo. Actualmente, el término peste se asocia a menudo con el bacilo Yersinia pestis, la peste negra que asoló Eurasia en 1347 y 1453 y mató un tercio de la población (unos veinticinco millones de personas). No obstante, las pestes de la Antigüedad griega y romana fueron causadas por otros patógenos, que en estudios recientes se cree que podrían ser de viruela, sarampión o tifus, entre otros, que se transmitían entre animales y personas. Los antiguos normalmente identificaban estas enfermedades asoladoras con castigos de la cólera divina. ${ }^{1}$

${ }^{1}$ En ese aspecto los judíos han sido los que más han explorado este concepto uniéndolo con otros males como guerra, hambre, terremotos..., y que tan intensamente padecieron los hijos de Jehová. De ahí procede el futuro concepto cristiano de los cuatro Jinetes del Apocalipsis (una interpretación de sus integrantes es la de Hambre, Peste, Guerra y Muerte), que son vistos como 
Por otro lado, el vocablo "epidemia” procede del griego epidêmía y tenía que ver inicialmente con las visitas que hacía el médico por motivo de una enfermedad. El término griego para pestis era loimós, pero luego (y ya se va viendo en algunos tratados hipocráticos) fue adquiriendo el sentido de peste, de esparcimiento de una enfermedad, de tal manera que los dos significados acabaron, de alguna forma, conjugándose. Normalmente, en la palabra pestis y sus derivaciones (pestifer, pestilentia, etc.) se atribuía la causa al aire corrupto, las aguas o comidas malsanas, y son referidas constantemente por una gran pléyade de escritores romanos como Cicerón, Columela, Virgilio, Varrón, Livio, etc. Se trataba, por lo tanto, de un tema de gran relevancia que se enfocó según diversos géneros, desde la historia y la épica hasta la tratadística médica y naturalista.

Uno de los primeros que describió con dramatismo y belleza retórica los estragos de una epidemia en el mundo occidental fue el historiador griego Tucídides, en la peste de la Atenas del año 430 a.C., que se llevó la vida de casi un tercio de la población (entre ellos, la figura emblemática de Pericles). Precisamente, la peste que narra Tucídides (que se llegó a llamar "síndrome de Tucídides") será el principal referente de las distintas epidemias ${ }^{2}$ que se enmarcan en Roma, desde la perspectiva tanto histórica como literaria, desde sus inicios monárquicos hasta prácticamente la época de los Antoninos y de Justiniano. Veamos un pasaje que Gozalbes Cravioto y García García seleccionan y en el que

un bloque de calamidades de la furia divina causado por el pecado humano, que llegarán en el final de los tiempos.

${ }^{2}$ Roy Porter afirma que a partir de la expansión griega, con la difusión de la civilización y el intercambio de mercancías, mercaderes, marineros y merodeadores empezó "the era of catastrophics epidemics", que se hizo frecuente y cada vez más elevada con los viajes y guerras de conquista, además del aumento poblacional y de insalubridad de las ciudades y la llegada de migrantes del campo y de otras localizaciones. Esta era tuvo sus puntos álgidos en el Egipto que relata el Antiguo Testamento, la Atenas de Tucídides o, especialmente, la Roma imperial, cuando "its legions conquered the known world, deadly pathogens were given free passage arount the Empire, coming home to the Eternal City itself". Blood and guts. A short history of medicine (Londres: Penguin Books, 2003), 7-8. Esto último queda de manifiesto en la peste de los Antoninos, que llegó a matar a un cuarto de los habitantes de aquel entonces, entre 165 y 180 millones de personas. 
se pueden apreciar los motivos "patheticos" del cuadro descriptivo de la peste:

[N]i el temor de los dioses ni de las leyes humanas detuviera a nadie; por una parte, les daba igual mostrarse piadosos o impíos, puesto que veían a todos morir por igual y, en caso de actos criminales, nadie lograba vivir lo suficiente para que tuviera lugar el juicio y pudiera saber su castigo; por el contrario, mucho más pesada era la amenaza por la que ya estaban condenados y, antes de verla abatirse, ellos consideraban justo el disfrutar algo de la vida. ${ }^{3}$

En la época de los Antoninos, el síndrome de Tucídides adquirió un nuevo enfoque, al menos desde la perspectiva de sus causas y condiciones sociohistóricas. Así pues, hasta los Antoninos las pestes en Roma fueron esencialmente locales, como en la propia Atenas. No olvidemos al respecto que Roma fue una polis igual que la Atenas del siglo V, que posteriormente se engrandeció y se acabó convirtiendo en un imperium. Como polis que fueron tanto Atenas como Roma, las enfermedades estaban localizadas y contenidas. ${ }^{4}$ Parece ser que según la opinión generalizada de expertos, si la peste de Atenas fue provocada por el tifus, las sucesivas pestes romanas de la época republicana se debieron a la malaria, causada por la vecindad de pantanos. Más adelante, estas epidemias fueron controladas bastante bien, quizá por la influencia decisiva de médicos griegos que llegaron a Roma a partir del siglo III a.C., y que, al seguir el método hipocrático, impulsaron la higienización de la ciudad.

El patrón localista comenzó a variar con la expansión romana. La Roma republicana era una ciudad Estado separada del resto de ciudades y pueblos que la rodeaban como volscos, samnitas, umbros, etc. Las pestes, durante el periodo republicano, ocurrían prácticamente cada año

${ }^{3}$ Tucídides II, 53, 4; tomado de: Enrique Gozalbes Cravioto e Inmaculada García García, "Una aproximación a las pestes y epidemias en la antigüedad", Espacio, Tiempo y Forma 26 (2013): 71, nota 31.

4 "En Grecia las pestes constituyeron fenómenos por lo general estrictamente locales, lo que venía favorecido por la propia atomización política del mundo griego, y por unas comunicaciones realizadas sobre todo por mar." Ibid., 72 . 
o cada poco tiempo y no tenían un impacto excesivo. Varios historiadores romanos relatan estas epidemias, como Tito Livio, Veleyo Patérculo, Dion Casio o el propio Julio César. ${ }^{5}$

Ya en época imperial, las epidemias comenzaron a espaciarse y se concentraron intensamente en momentos puntuales. Así, por ejemplo, en época de Nerón y los Flavios, tanto Tácito, como Séneca ${ }^{6}$, Plinio, Suetonio o Celso refieren la extensión de enfermedades de la piel como la lepra ${ }^{7}$ o de una fuerte peste en el año 78 d.C., con Vespasiano. Todas estas epidemias del periodo imperial mostraron cambios en las infecciones, que de ser anuales se volvieron más espaciadas, pero con mayor impacto poblacional y socioeconómico: eran el caldo de cultivo para una "unificación microbiana", una " "globalización' de bacilos y bacterias" que tuvo su eclosión en época de los Antoninos, cuando entre 165 y 170 estalló y se expandió una fortísima pandemia, que pudo haber provocado varios brotes posteriores o ser el desencadenante de nuevas y virulentas epidemias. Esta peste, según diferentes estudios, pudo ser producida por el sarampión o incluso la viruela (de hecho, causó estragos muy similares a los de la propia viruela con la llegada de los españoles a América). ${ }^{9}$ Por otro lado, supuso un "nuevo ciclo sanitario

5 "Plinio habla de, al menos, once epidemias en los tiempos de la República, y hay constancia de episodios (plagas o pestes) en 174, 142, 87, 58, 46 y 43 a.C." Agustín Muñoz-Sanz, "Marco Aurelio Antonino (121-180 d.C.), filósofo y emperador de Roma, y la peste de Galeno", Enfermedades Infecciosas-Microbiología Clínica 30, núm. 9 (2012): 553.

${ }^{6}$ Séneca refiere en época de Nerón que están llegando a Roma nuevas enfermedades extrañas y que ello se debía a "la intemperancia de los nuevos tiempos". Las constantes referencias a la peste como símbolo metafórico con el que el filósofo estoico compara distintos vicios humanos (vitia), muestra la relevancia que tuvieron las enfermedades contagiosas durante el periodo del dominio de Nerón. Incluso en sus Cuestiones naturales (6, 27-29), Séneca llega a decir simbólicamente que los vitia constituyen el origen de las propias epidemias humanas.

${ }^{7}$ En época de los Flavios, Plinio refiere la expansión, excepto en Galia e Hispania, de nuevas enfermedades de la piel cuyo origen atribuye a Egipto; entre ellas, destaca la lepra (o elefantiasis), que llevaba bastante tiempo ya extendiéndose.

${ }^{8}$ Enrique Gozalbes Cravioto e Inmaculada García García, "La primera peste de los Antoninos (165-170): Una epidemia en la Roma Imperial”, Asclepio 59 (2007): 17.

${ }^{9}$ No se tiene nada clara la etiología de esta peste, ya que también se habla de tifus exantemático, gripe, disentería, varicela, cólera, peste pulmonar, peste bubónica. Ibid., 20. De todas, la viruela es la que más adeptos tiene, "siendo razonable concluir que probablemente fue en este momento, y en otras pandemias posteriores, cuando dicha afección tuvo fuerte incidencia inicial en las poblaciones mediterráneas, terminando por convertirse en endemia infantil". Ibid., 21. 
después de varios siglos en una situación bastante benevolente" y fue la principal consecuencia de la "globalización" imperial ${ }^{10}$ que empezó a verse con las enfermedades cutáneas de época de Nerón y que alcanzó su clímax en la peste antonina. Por último, hubo otras dos destacadas pandemias: en 180, la época del hijo de Marco Aurelio, Cómodo (algunos especialistas creen que pudo haber sido la primera aparición de la peste bubónica), y la de Justiniano entre 541 y 544, ya al comienzo de la Edad Media, que se extendió de Constantinopla a prácticamente toda Europa y que por su sintomatología los expertos consideran que ya era la propia peste bubónica que llegó para quedarse.

\section{Efectos políticos y sociales de pestes y pandemias}

El enfoque socioeconómico va íntimamente ligado al histórico y, a continuación, estudiaremos factores que ofrecen grandes semejanzas con la situación provocada por la pandemia del actual covid-19 de 2020. Para el presente enfoque tomaremos de referencia el análisis de uno de los textos en que el historiador romano Tito Livio relata los estragos sociales y económicos que provocó una peste en la época republicana y su reacción política hacia el siglo $\mathrm{V}$ a.C.:

Después de un año tranquilo gracias a la moderación de los tribunos, apareció el tribuno de la plebe Lucio Icilio, siendo cónsules Quinto Fabio Ambusto y Gayo Funo Pacilo. Cuando este, ya desde que comenzó el año, igual que si se tratara de una obligación de su nombre y su familia, promovía disturbios a propósito de la promulgación de leyes agrarias, brotó una epidemia, más amenazadora no obstante que dañina, que desvió del foro y los enfrentamientos públicos la atención de la gente hacia el hogar y los cuidados de la salud; se cree que fue menos perjudicial de lo que lo hubiera sido la sedición. Cuando la población salió del trance a costa de muchísimos casos de enfermedad y contados casos de fallecimiento, tras el año de peste, debido al abandono, corriente en estos casos, del cultivo de los campos vino la falta de alimentos, durante el consulado de Marco

${ }^{10}$ Ibid. 
Papirio Atratino y Gayo Naucio Rútulo. El hambre hubiera sido más funesta que la epidemia, si no se hubiese asegurado el aprovisionamiento de víveres enviando legados a todos los pueblos que habitan en el contorno del mar de Etruria en las riberas del Tiber a comprar trigo. Los samnitas, a los que pertenecían Capua y Cumas, impidieron con arrogante actitud que los legados comprasen; por el contrario, los tiranos de Sicilia les ayudaron de buen grado; los contingentes mayores, al poner en ello Etruria su mejor voluntad, bajaron por el Tiber. Los cónsules tuvieron una prueba de la falta de hombres en la población enferma, cuando se vieron forzados, al no encontrar nada más que un senador para cada legación, a sumarle dos caballeros. Enfermedad y provisión de víveres aparte no hubo durante aquellos dos años ningún problema interno y externo. Pero, cuando aquellas preocupaciones desaparecieron, surgió todo lo que solía inquietar a la ciudad: en el interior la discordia, en el exterior la guerra. ${ }^{11}$

En este texto se pueden apreciar los problemas sociales y económicos que causan las epidemias, a saber:

- Confinamiento en los hogares.

- Los problemas políticos pasan a un segundo lugar ante los de la salud. De esta forma, la política se olvida de sus rencillas internas para proteger a su población.

- Baja productividad económica ("abandono [...] del cultivo de los campos").

- Carestía alimenticia.

- Tensión con otros pueblos (los samnitas) por la búsqueda del aprovisionamiento de alimentos.

De hecho, en este último aspecto podemos apreciar el comienzo de males mayores, como sucede que, con esas tensiones que produce la plaga epidémica, se da pie a otra "plaga" más grave que es la de la "discordia interna" y de la "guerra" externa. El ejemplo de la historia de Roma nos enseña que, prácticamente, todos los avatares tanto políticos,

${ }^{11}$ Tito Livio, Historia de Roma desde su fundación, trad. por José Antonio Villar Vidal (Madrid: Gredos, 1990), 4, 52-53. 
como económicos y sociales que Roma ha padecido a lo largo de su historia se han repetido casi con minuciosidad en el mundo moderno. Así lo podemos ver en el hedonismo de emperadores caprichosos y oportunistas (en el mundo actual las figuras políticas que dominan el panorama internacional muestran una gran semejanza con los Calígulas, Nerones o Cómodos); el paso de un sistema más o menos democrático a sistemas absolutistas, como es el cambio de la República por el Imperio; los flujos político-económicos como una suerte de liberalismo comercial que se dio en época de los Antoninos, floreciente y deslumbrante en sus relaciones comerciales; o el absolutismo estatalista a la que se entregó la tetrarquía de Diocleciano con un fuerte control impositivo y burocrático. La historia de Roma es un ejemplo claro de todo lo que el ser humano moderno puede llegar a hacer. Y no es menos cierto con el tema de la peste y la pandemia. En el fragmento citado de Livio se aprecian todos los factores sociales y políticos que provoca una enfermedad infecciosa de estas características, además de los riesgos futuros, como los altercados sociales internos o los conflictos políticos y diplomáticos entre naciones. Ahora mismo sucede algo similar, y comprobamos cómo en muchos países la pandemia está provocando una guerra interna callada pero preocupante, a la vez que surgen resquemores y viejos rencores, ocasionados por la venta fraudulenta de suministros de salubridad o por las tensiones que se generan con la nación de donde procede la pandemia (China ya refiere que Estados Unidos quiere otra nueva Guerra Fría y también da la impresión de que China se aprovecha económicamente de este momento crítico para golpear a su enemigo políticoideológico).

En el siguiente texto, el historiador latino Tácito habla de una peste que asoló el imperio durante el periodo neroniano, en el siglo I d.C., y añade otros factores de los problemas socioeconómicos que genera una epidemia infecciosa en el tejido estatal de la población:

13. Aquel año manchado por tantos crímenes, se vio distinguido todavía por los dioses con tempestades y epidemias. Fue asolada la Campania por un huracán que por todas partes destrozó villas, árboles y cosechas, haciendo llegar su fuerza hasta las cercanías de la Ciudad, en la cual, entretanto, 
el género humano se veía devastado por una peste sin que el cielo mostrara señales visibles de perturbación. Pero las casas se llenaban de cuerpos exánimes, las calles de duelos. No respetaba el peligro sexo ni edad; morían repentinamente por igual esclavos y plebeyos libres, en medio de las lamentaciones de cónyuges e hijos, que por haber permanecido a su lado llorándolos acababan a menudo ardiendo en la misma pira. Las muertes de caballeros y senadores, aunque se produjeron en cantidad, parecían menos dignas de llanto, como si padeciendo la común mortandad se adelantaran a la saña del príncipe. En el mismo año se hicieron levas en la Galia Narbonense, África y Asia, a fin de completar las legiones del Ilírico, en las cuales se licenciaba a los que estaban acabados por los años o las enfermedades. El desastre de Lyon recibió del príncipe un socorro de cuatro millones de sestercios destinados a reconstruir la ciudad, la misma cantidad que antes habían donado los lioneses para remediar las desgracias de Roma. ${ }^{12}$

En el texto se aprecian otros factores propios de una epidemia que podemos percibir hoy en día, como son los signos ominosos naturales que la anticipan o la equidad que produce la enfermedad. Afecta tanto a pobres y ricos; si hay algo equitativo, son la enfermedad y la muerte. La peste nos recuerda lo frágiles que somos y cómo no importa nada nuestro estatus social. La quema de cadaveres y las leyes estrictas de control de la epidemia se asemejan a las políticas sanitarias actuales ante las pandemias. Por otro lado, podemos apreciar en Roma un "pre-Estado del bienestar", en forma de ayudas monetarias por parte del príncipe, como ahora se observa en la forma en que diferentes países recopilan abundantes cantidades de dinero para invertir en la reconstrucción de estructuras sociales devastadas por la enfermedad. ${ }^{13}$

${ }^{12}$ Tácito, Anales, trad. por José L. Moralejo (Madrid: Gredos, 1980), 16, 13.

${ }^{13}$ Es innegable que durante estos periodos se impone el sistema keynesiano, no queda otra posibilidad más que el Estado intervenga estimulando el tejido productivo y financiero. Sin entrar en la polémica económica entre Keynes y Hayek, si es mejor la intervención estatal para proteger y conducir debidamente la economía bajo criterios humanos, o que el mercado funcione por la "mano invisible" dejado al azar y a la espontaneidad, sin intervencionismo alguno, es innegable que Hayek sí llegó a reconocer que en momentos de crisis intensas, que producen grandes bolsas de desempleo, el Estado sí debe intervenir para estimular y fomentar el regreso a cierta normalidad; ¿Nos queda entonces decir que el modelo de Keynes sirve para las crisis y el de Hayek para épocas equilibradas y de bonanza? 


\section{Origen religioso y médico de las epidemias: La teoría miasmática y humoral}

La principal causa de la peste es la cólera divina que emplea la enfermedad como castigo de venganza (némesis) ante nuestra hybris (insolencia, exceso, soberbia y osadía). De este modo, la peste se muestra como motor de un pensamiento mítico religioso que vertebra, por ejemplo, la obra de Edipo Rey de Sófocles, ${ }^{14}$ que tuvo presente, con seguridad, la peste de Atenas del siglo V a.C., y que posteriormente Séneca reproduce y recrea en un ambiente mitológico sombrío y tétrico, propio del estilo conceptista y retórico del estoicismo senequiano. ${ }^{15}$ Roma, muy dominada por un espíritu religioso prácticamente animista, con manes, penates y una incesante divinización de todo tipo de conceptos o elementos, propia de un fuerte casuismo politeísta, presentaba en el ámbito de la salud y la enfermedad a distintas divinidades sanadoras que procedían principalmente de los etruscos, como por ejemplo, Febril, diosa de las enfermedades de los pantanos, Meftis, dios de la fetidez, Scabies dios de la sarna, Salus, dios de la salud, cuya efigie, en el periodo de la peste de los Antoninos, se acuñó en las monedas romanas, o el más destacado, Esculapio, tomado del panteón griego.

El pensamiento religioso, que tiene a menudo una fuerte base supersticiosa y que se centra en la ascendencia mitológica y animista de los dioses, se plasma, en especial, en la teoría miasmática. Miasma (y su derivado miasmós) es un término griego que significa "mancha", "impureza", "contaminación" o "infección". Se trata de un vapor o exhalación "dinámica”, enviada por los dioses, y que parecía que tuviera una

14 "La ciudad como tú mismo puedes ver, está ya demasiado agitada y no es capaz todavía de levantar la cabeza de las profundidades por la sangrienta sacudida. Se debilita en las plantas fructíferas de la tierra, en los rebaños de bueyes que pacen y en los partos infecundos de las mujeres. Además, la divinidad que produce la peste, precipitándose, aflige la ciudad. ¡Odiosa epidemia, bajo cuyos efectos está despoblada la morada Cadmea mientras el negro Hades se enriquece entre suspiros y lamentos!" Sófocles, Edipo Rey, trad. por Assela Alamillo (Madrid: Gredos, 1981), 312.

15 "Ya expulsada la noche, vuelve Titán con luz indecisa y surge su luminaria, sin fuerza, tras negruzcos nubarrones; cuando esparza su triste luz de luctuosa llama, va a contemplar las casas desoladas por la peste voraz; y los estragos que ha causado la noche los va a mostrar el día.” Séneca, Edipo, trad. por Jesús Luque Moreno (Madrid: Gredos, 1980), 95. 
especie de vida propia; solo se podía purgar mediante sacrificios que, en caso de no hacerse, el individuo o comunidad continuaría sufriendo el castigo divino que los provocaba. Así pues, es lo que sucede con la peste de Tebas por el delito de hybris que ha cometido Edipo y que debe expiar con su propia inmolación. Estas ideas, procedentes de la mitología griega, pasaron a Roma, y cuando sucedía una peste "miasmática", los romanos debían tranquilizar a lo dioses mediante rituales y sacrificios, con el propósito de apaciguar su ira, la cual podría deberse a muy diversas razones. ${ }^{16}$ Posteriormente, la teoría miasmática ${ }^{17}$ fue empleada en la medicina tanto de Hipócrates como de Galeno y adquirió un sentido racional por el que quedó excluido el elemento supersticioso y divino, con lo que los miasmas se conjugaron con la teoría de los cuatro humores (sangre, flema, bilis amarilla y bilis negra) que se fundamenta en los cuatro elementos (aire, agua, fuego, tierra) que conforman la realidad natural, según anteriores tesis presocráticas (por ejemplo, la filosofía de Empédocles basa toda su explicación del origen de la naturaleza en la organización de los cuatro elementos).

El cuerpo del hombre tiene en sí mismo sangre, pituita, bilis amarilla y bilis negra; estos elementos constituyen la naturaleza del cuerpo, y por causa de ellos se está enfermo o sano. Se goza de una salud perfecta cuando están mutuamente proporcionadas sus propiedades y cantidades, así como cuando la mezcla es completa. Por el contrario, se enferma cuando alguno de los elementos se separa en mayor o menor cantidad en el cuerpo y no se mezcla con todos los demás. ${ }^{18}$

${ }^{16}$ Por eso mismo, con el fin de evitar esa ira en la guerra siempre se consultaba a los arúspices, con el propósito de hallar el momento apropiado para iniciar la batalla. La declaración de guerra siempre debía tener un casus belli lícito, para evitar el castigo divino al que se llegaba por agredir injustamente al otro.

${ }^{17}$ Esta teoría adoptó su versión moderna en las propuestas del químico alemán Justus von Liebig (1803-1873), que aseguraba que la fermentación de la sangre produce gases tóxicos que provocaban diversas enfermedades como cólera, viruela o sífilis, y que el aire transportaba, uniéndose con los provenientes de la descompensación de la materia orgánica de la tierra. Esta tesis fomentó mucho la higienización en el siglo XIX, porque se consideraba que los barrios pobres y sucios estaban "infectados" de miasmas y había que limpiarlos y purgarlos para evitar las enfermedades epidémicas.

${ }^{18}$ Hipócrates, Sobre la naturaleza del hombre, trad. por Jorge Cano Cuenca (Madrid: Gredos, 2003), 37. 
En el ámbito de esta teoría, Hipócrates consideraba que los desequilibrios de los humores eran de origen interno o externo. En el caso interno, los humores alteraban por una mala dieta; y en el externo, por aires que se introducían en el cuerpo. En ese punto vemos la relación con la teoría miasmática, con la diferencia de que, en vez de que el "aire" (pneuma) provenga de los dioses, procede necesaria o casualmente de la propia naturaleza:

Las enfermedades surgen o de la dieta o del aire que inspiramos al vivir. El diagnóstico de cada uno de estos tipos ha de hacerse del siguiente modo: cuando multitud de personas sucumben a una misma enfermedad en un mismo periodo de tiempo, se debe atribuir la causa a lo que es más común y de lo que todos nos valemos en mayor grado: eso es, el aire que respiramos. ${ }^{19}$

De hecho, ese pneuma se mezcla con los líquidos de los humores corporales y produce apókrisin, ${ }^{20}$ que es una secreción líquida, contaminada por la emanación o exhalación de un pneuma excesivo o entorpecedor que acaba corrompiendo las secreciones y los líquidos humorales. ${ }^{21}$

${ }^{19}$ Ibid., 47.

20 "But when an epidemic of one disease is prevalent, it is plain that the cause is not regimen but what we breathe, and that this is charged with some unhealthy exhalation." Hippocrates, "Nature of man", trad. por W.H.S. Jones (Cambridge: Harvard University Press, 1931), IV, 27. El noseren [...] apokirisin (ibid.) es la "exhalación poco saludable" o "enfermiza". Es ese aire que corrompe los líquidos humorales y por lo tanto desequilibra la eyctasía del cuerpo.

21 "La idea de que el hombre está inmerso en su medio ambiente y es una pieza más dentro del enorme espacio cósmico que lo rodea se manifiesta de modo singular en la teoría del pneuma (pneûma), tal como aparece recogida en varios escritos hipocráticos. El pneuma, nos dice el autor de Sobre los flatos, se llama "aire" (aêr) cuando está fuera del cuerpo y "flato" (physa), cuando se encuentra dentro. La misión más relevante del pneuma dentro del cuerpo humano es alimentar, impulsar y refrescar. El aire, a juicio de los hipocráticos, penetra en nuestro cuerpo por nariz y boca, mas también por medio de los poros. La respiración cutánea, en efecto, aparece formulada en varios tratados. En el cerebro, el pneuma es el encargado de producir la inteligencia, lo cual está en consonancia con las lucubraciones de ciertos presocráticos, para quienes el aire resultaba ser el elemento inteligente y conductor del universo. Posteriormente, el pneuma se mezcla con la sangre y pasa a pulmones y corazón y se difunde por vasos a todo el cuerpo. Pero si el pneuma queda detenido o entorpecido en algún punto del cuerpo, allí precisamente se produce el dolor y la enfermedad." Juan Antonio López Férez, "Hipócrates y los escritos hipocráticos: Origen de la medicina científica”, Epos 2 (1986): 169-170. 
Mostramos en la siguiente imagen ${ }^{22}$ los cuatro humores correspondientes a los elementos y a aspectos del comportamiento y el carácter, más los factores astrológicos, lo que muestra el equilibrio entre hombre (alma y cuerpo), naturaleza y cosmos:

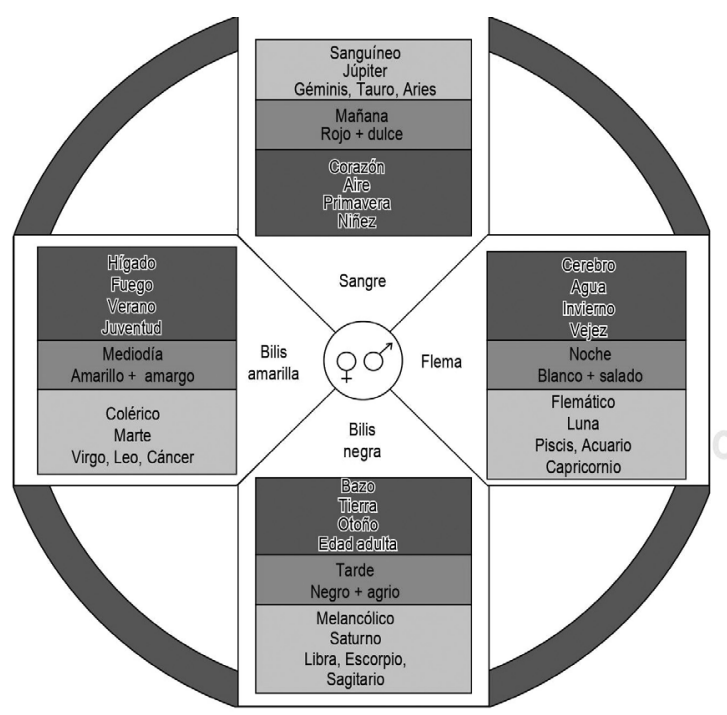

La teoría humoral y miasmática predominó desde la Antigüedad grecorromana hasta prácticamente el siglo XIX, lo que no quiere decir que no hubiera alternativas a la explicación de la propagación de las enfermedades infecciosas, como veremos en el siguiente apartado.

\section{La teoría "microbiana" de los antiguos romanos: Lucrecio y Varrón}

Tanto la explicación médica de los humores como la de los miasmas fueron sustituidas a finales del siglo XIX por la tesis microbacteriana

22 "La figura muestra la teoría según Hipócrates (en gris oscuro), las modificaciones realizadas por Galeno (en gris claro) y la ampliación medieval (en gris más tenue)." Bayer, Crónica de la medicina (Barcelona: Plaza y Janés, 1994) 55; tomado de: Andrés Romero y Huesca et al., "Galeno de Pérgamo: Pionero en la historia de la ciencia que introduce los fundamentos científicos de la medicina", Anales Médicos 56, núm. 4 (2011): 221. 
y la teoría germinal de las enfermedades infecciosas de Louis Pasteur (1822-1895), quien explica la propagación de las enfermedades por obra de gérmenes microbiológicos, bacterias y virus, es decir "pequeños cuerpos" que se reproducen en el organismo. Esta teoría, contra lo que pudiera suponerse, se puede ver aludida, con las diferencias correspondientes, en el De rerum natura, de Tito Lucrecio Caro (99-55 a.C.), quien, siguiendo la concepción materialista de Demócrito y Epicuro, propone que la materia está formada por "cuerpos elementales" (cacumen corporis), que son "invisibles a nuestros sentidos". Son los átomos democríteos y epicúreos que el escritor romano define como primordia (rerum) o semina (rebus). ${ }^{23}$ Seguidamente, con base en los principios fundamentales de esta teoría, propone su explicación corpuscular de las infecciones y de las epidemias y pestes, antes de mostrar todo el cuadro impresionante en que recrea la peste de Atenas de Tucídides:

Te explicaré ahora cuál es la causa de las enfermedades, de dónde viene tan de súbito esta fuerza maligna (morbida vis) capaz de esparcir la muerte entre hombres y rebaños. En primer lugar, mostré más arriba que hay gérmenes de numerosas sustancias (multarum semina rerum) ${ }^{24}$ que nos dan vida (vitalia), y al contrario es innegable que vuelan por el aire muchos gérmenes de enfermedad y de muerte (morbo mortique necessest multa volare) $[. .$.$] . Cuando un azar o accidente ha reunido estos últimos e$ infectan el cielo (perturbarunt caelum), el aire se hace pestilente (morbidus aer). Y toda esta fuerza morbosamente y pestífera (vis omnis morbosamente pestilitasque), o viene de regiones exteriores a través del cielo, como

23 "Los átomos (primordia) son, pues, sólidos y simples, formando un todo coherente de partes mínimas, apretadamente trabadas, y no proceden de la combinación de estas partes, sino que son fuertes por su eterna simplicidad, y la naturaleza no permite que nada se arranque de ellos ni mengüen en nada, reservándolos como semillas de las cosas (semina rebus). " Lucrecio, De la naturaleza, trad. por Valentí Fiol (Barcelona: Acantilado, 2012) 1, 610-615.

${ }^{24}$ No creemos que la traducción de semina por "gérmenes" sea la más adecuada, ya que, aunque la RAE (https://dle.rae.es/germen), en su segunda acepción, la define como "parte de la semilla de que se forma la planta", que es la acepción que debe entenderse para el sentido que Lucrecio le da a la palabra en el texto propuesto, no obstante normalmente se le toma por su cuarta acepción de "microorganismo patógeno". Por eso mismo, para no confundirse con los virus infecciosos que descubrió Pasteur, es mejor traducirlo por "semillas". Francisco Socas, en su traducción de Lucrecio [La naturaleza (Madrid: Gredos, 2003), 440], lo hace con el término de "simientes" que también es, desde nuestro punto de vista, más afortunado que "gérmenes". 
las nubes y neblinas, o a menudo se reúne y emerge de la tierra misma, cuando el húmedo suelo (umida) entra en corrupción al embate de intempestivas lluvias y calores. ${ }^{25}$

Ambos semina forman parte de la construcción atómica del universo. La concepción corpuscular lucreciana se podría dividir en: 1) átomos físicos que forma la realidad al moverse; 2) átomos biológicos que confieren vida y fuerza a los seres vivos; ${ }^{26}$ y 3 ) átomos infecciosos, que son considerados como agentes microscópicos que transmiten enfermedad y contagio. De este modo, si los primeros son inanimados, los segundos son vivos y los terceros ni vivos ni muertos. La relación con las partículas que forman la realidad es evidente. Se puede decir que los semina que dan vida son como las células que constituyen la base del crecimiento y de la salud, pero en el caso de los semina infecciosos son como los virus, que ni están vivos ni muertos. Por otro lado, es digno de destacar que esos semina infecciosos vuelan por el aire y corrompen las aguas al caer en ellas. Vemos así de qué modo, sobre la base hipocrática y miasmática, Lucrecio confiere un nuevo sentido a la propagación de las enfermedades epidémicas. De hecho, además de dar un origen a las enfermedades contagiosas también recrea literariamente el contagio y expansión de la peste de Atenas, sobre el referente del griego Tucídides:

Pero allí lo más triste y lastimero era que, apenas se veía uno presa del contagio, perdía todo ánimo y yacía inmóvil, creyéndose condenado a morir, el corazón henchido de tristeza, y pensando solo en la muerte rendía la vida allí mismo. En efecto, en ningún momento el contagio del mal insaciable cesaba de irse comunicando de uno a otro, como en lanosos carneros o en un rebaño de bueyes. Esta era, sobre todo, la causa que apilaba

${ }^{25}$ Lucrecio, De la naturaleza, 6, 1090-1035.

${ }^{26}$ En cuanto a los semina vitalia, se refiere a ellos en varias partes del libro primero: "pues voy a explicarte la razón última del cielo y de los dioses, y a revelarte los elementos primeros de las cosas con los que la Naturaleza crea los seres, los nutre y hace crecer, y en los que los resuelve de nuevo una vez destruidos; a estos elementos solemos llamarlos, al exponer nuestra doctrina, materia, cuerpos genitales o semillas de las cosas y también les damos el nombre de cuerpos primeros, porque de ellos, como sus principios, nacen todos los seres". Ibid., 1, 50-60. 
muertes sobre muertes; pues todos los que evitaban visitar a sus parientes enfermos, por codicia excesiva de la vida y temor a la muerte, eran a poco castigados con muerte vil y miserable y parecían abandonados, privados de recursos, víctimas del abandono. Por otra parte, los que habían asistido a los suyos, sucumbían al contagio y a la fatiga, que aceptaban forzados por su honor y por el suplicante acento de los moribundos, entremezclado con quejas. Los mejores se exponían a esta clase de muerte. ${ }^{27}$

Junto con Lucrecio, el escritor latino Varrón se adhirió a la postura de que las pestes son provocadas por elementos "diminutos", y propuso que el origen de la "pestilencia" está en unos animalia minuta que se forman en los lugares pantanosos y que pueden esparcirse por el aire:

También, si hay lugares pantanosos, hay que colocarla en sentido contrario, no solo por las causas citadas sino también porque crecen ciertos animales minúsculos que no pueden ser vistos por los ojos y que penetran por el aire a través de boca y narices en el cuerpo y causan graves enfermedades. "¿Qué podré hacer”, dice Fundanio, "si consiguiera en herencia una finca de este estilo, para que la pestilencia dañe menos?". "A esto también puedo responder yo", dice Agrio: "que la vendas por cuantos ases puedas, y si no puedes, que la dejes". ${ }^{28}$

Por eso mismo, las casas deben evitarse "hacia los lugares desde los que suela soplar el viento más malsano" y no deben edificarse en "lo profundo de un valle, sino antes bien en lugar alto que, como está muy ventilado, si algo se manifiesta en contra, más fácilmente se disipa" ${ }^{29}$ Ese aire sano y la iluminación del sol hará la casa más saludable, "porque también los animalillos (bestiolae), si algunos nacen cerca y se introducen, o se dispersan por el viento o perecen pronto por la sequedad". ${ }^{30}$ Como ya hemos visto, la base de todas estas teorías es la miasmática y

${ }^{27}$ Ibid., 6, 1230-1246.

${ }^{28}$ Varrón, Rerum rusticarum libri III, trad. por Ignacio Cubero Salmerón (Sevilla: Junta de Andalucía, 2010), 1, 12,1.

${ }^{29}$ Ibid.

${ }^{30} \mathrm{Ibid}$. 
sobre esta Varrón, influido por teoría atomista o incluso por Lucrecio, ${ }^{31}$ propuso que los elementos que contagian y traen enfermedades pestíferas son pequeños seres vivientes, que, por su tamaño, se asemejarían a los atomoi o a los semina del escritor del De rerum natura. Como escribe Prioreschi, las afirmaciones de Varrón son impresionantes, ya que en plena Antigüedad se acercan a la "germ theory of disease of our time", de modo que "as the agents causing disease were small animals, the idea came later to be known as the animacular hypothesis of disease, as opposed to the miasmic hypothesis, which goes back to Hippocrates". ${ }^{32}$ De este modo, para Varrón, si existen partículas diminutas que conforman la naturaleza, ¿por qué no podría haber pequeños animales que flotan en el medio natural? ${ }^{33}$ Así pues, las tesis de Varrón proceden de tres raíces: el epicureísmo atomista, el enfoque lucreciano y las semillas de las enfermedades.

Prioreschi considera que la teoría de Varrón (y del mismo modo, podemos pensar que la de Lucrecio) no pervivió porque no era práctica e iba en contra del pragmatismo romano, ya que "the idea that incredibly small organisms can cause disease is against the good sense that (sometimes) governs human beliefs". ${ }^{34}$ Resultaba "ridículo" que unos

24 "animalitos" invisibles entraran por la nariz y boca sin que fueran percibidos y que provocaran las enfermedades, y no unos vapores o exhalaciones que se ven y perciben y, la mayor parte de las veces, producen reacciones respiratorias dificultosas. Por otro lado, la tradición hipocrática basada en el pneuma y reforzada por los escritos y descripciones

${ }^{31}$ De hecho, al igual que Lucrecio trata de "semillas", y refiere, siguiendo a Anaxágoras y a Teofrasto, que la "simiente, que es el principio de la reproducción, es de dos tipos, uno que se esconde a nuestros sentidos, el otro que es visible"; ibid., 1, 40,1. Las semillas que hay en el aire son invisibles, como afirma Anaxágoras, y las suele llevar el agua, tal como dice Teofrasto. Con ello, Varrón se inserta en la tradición presocrática materialista y pluralista que, además de Lucrecio, tiene como referente a Anaxágoras y su teoría de que las cualidades de un todo están conformadas por partes mínimas que tienen esas mismas cualidades (los spermata).

${ }^{32}$ Plinio Prioreschi, A history of medicine (Omaha: Horatius Press, 1998), III, 216.

33 "If there are particles so small that they cannot be seen (atoms), and if there are animals so small that their hearts and organs are invisible, why not animals whose whole body is so small that they cannot be seen?" Ibid., 220.

${ }^{34}$ Ibid., 221. 
de Plinio el Viejo, ${ }^{35}$ coadyuvó con los miasmas para reforzar las tesis de que son simplemente los malos aires los que producen las epidemias y las actuales pandemias. Aunque la tesis predominante fue la miasmática humoral que vino a ser reforzada por el propio Plinio el Viejo, la lucreciana y el varroniano ejercieron cierta influencia. El propio Séneca llegó a conjugar en sus Naturales quaestiones la teoría de los semina de Lucrecio ${ }^{36}$ con los miasmas hipocráticos que se producen en las "entrañas de la tierra", donde se "ocultan aguas nocivas y malsanas" que se impregnan de "muchas sustancias letales" (mortifera) y "numerosos venenos" (venena), que "nacen en ella, no sembrados por la mano del hombre sino espontáneamente, sin duda porque el suelo contiene gérmenes (semina) tanto beneficiosos como nocivos". ${ }^{37}$ En esta última afirmación se puede entrever la teoría de Lucrecio sobre las semillas "que nos dan vida" (vitalia) o las "de enfermedad y muerte" (morbo mortique).

Por otra parte, se aprecia la influencia del pensamiento mítico-religioso por el que las epidemias son interpretadas como némesis de los dioses, cuando identifica las consecuencias malignas de la peste con el término vitia, cuyo sema inicial es un tecnicismo de la lengua de los augures que tiene que ver con la irregularidad y anomalías de los auspicios:

La duración de la mortandad es más breve o más larga según la fuerza del veneno, y la peste no cesa hasta que a aquel aire malsano no lo dispersaron la amplitud del cielo o el soplo del viento. ${ }^{38}$

${ }^{35}$ Prioreschi, con cierto escepticismo, también añade las tesis de William H. Stahl [Roman science: Origin, development, and influence to the later Middle Age (Madison: The University of Wisconsin Press, 1962), 135], que vienen a decir que por la mayor fama, relevancia y fascinación que producía la Historia Natural de Plinio el Viejo la teoría miasmática acabó por superar el pensamiento teórico y sistemático de la Enciclopedia varroniana.

${ }^{36} \mathrm{~A}$ pesar de mostrarse en varios aspectos contrario al epicureísmo, Séneca como científico crítico tuvo en consideración las propuestas de Epicuro y, de hecho, siguió de cerca a su principal discípulo romano, Lucrecio, al que, además consideraba un gran poeta.

${ }^{37}$ Séneca, Cuestiones naturales, trad. por José-Román Bravo Díaz (Madrid: Gredos, 2013) 6, 28, 1. Para los términos en latín hemos seguido la edición de Teubner: Séneca, Opera quae supersunt, ed. por Alfred Gercke (Leipzig: B.G. Teubner, 1939), II, 228.

${ }^{38}$ Ibid., 6, 28, 3. 
El "veneno" (vitia) que genera la peste puede ser interpretado por el lexema de la palabra como una suerte de irregularidades celestes que son transportadas por el "aire malsano", hasta que los dispersa la "amplitud del cielo" y el "soplo del viento" (los cuales podrían verse como fenómenos naturales de una alegoría divina).

Por último, más alla del ámbito de la filosofía natural y de la religiosidad, Séneca además identifica la peste con los vicios humanos, como sucede en el siguiente pasaje de De tranquillitate animi:

A los amigos hemos de elegirlos vacíos, en cuanto fuere posible, de deseos; poque los vicios (vitia) entran solapados y asaltan al que está cerca y lo dañan con su contacto. Así como en una epidemia (pestilentia) hay que tener cuidado de no acercarse a cuerpos ya atacados y ardiendo en la enfermedad, porque atraemos el peligro y con la misma respiración nos exponemos al contagio, del mismo modo al elegir los amigos hemos de cuidar de tomar a los menos manchados (inquinatus) $;{ }^{39}$ el principio de la enfermedad es mezclar a los sanos con los enfermos. ${ }^{40}$

El filósofo cordubense pretende relacionar este tipo de epidemias y pestes con una degradación moral de los seres humanos o de la sociedad en general. Las enfermedades y plagas serían producto del declive ético, que es propio de una filosofía como el estoicismo senequiano, que se basa en una estructura de fuertes connotaciones ético-religiosas. Así pues, el pasaje anterior es un buen ejemplo de la frecuencia con que Séneca comparaba las cuestiones éticas con las médicas y, en definitiva, veía al filósofo estoico como un médico de alma.

En resumen y a modo de conclusión del apartado, la teoría humoral y miasmática será la que prevalecería frente al "atomismo infeccioso",

${ }^{39}$ Inquinatus, participio del verbo inquino, es un verbo derivado que tiene un origen etimológico en cunire con el prefijo-preposición in, que significa "producir estiércol". Con el paso del tiempo pasaría del plano estrictamente físico al sentido nocional y significaría no solo "ensuciar" y "enfangar", sino también "corromper" y "deshonrar". En este término se puede ver la perfecta conexión de cómo la pestilentia genera una mancha no sólo física de sus pústulas y erupciones, sino también moral por una degradación de los actos éticos y la conducta.

${ }^{40}$ Séneca, De la tranquilidad del ánimo, trad. por José M. Gallegos Rocafull (México: UNAM, 1944) 6, 3. La referencia a los términos latinos es la misma de la edición de Gallegos Rocafull. 
de Lucrecio y Varrón, y a pesar del pequeño impulso senequiano. De la misma forma que las tesis materialistas democríteas difundidas por Epicuro y Lucrecio cayeron en el olvido ante las filosofías platónicas, aristotélicas y estoicas, en el campo de la salud sucedió lo mismo con la medicina hipocrática y galénica, que triunfó y predominó a lo largo de la historia de la Europa occidental hasta el siglo XIX, por lo que las tesis lucrecianas y varronianas fueron dejadas de lado hasta que a finales del siglo XIX, los experimentos de Louis Pasteur con el virus de la viruela acabaron demostrando que la explicación corpuscular de pestes y epidemias acertaba más al origen y causa de las enfermedades contagiosas que las tesis de Hipócrates, Galeno y sus continuadores.

\section{Conclusiones}

Hemos recorrido un panorama más o menos minucioso de cómo se comportaban las pestes, epidemias y pandemias en la Antigüedad clásica grecolatina. Así, pudimos demostrar la gran similitud entre los comportamientos políticos y sociales que provocaron las pestes en la antigua Grecia y la antigua Roma, en íntima semejanza con las alteraciones socioeconómicas que el virus covid-19 produce ahora mismo en el mundo. Por otro lado, los clásicos ofrecen diversos modos de explicar las enfermedades infecciosas: mediante la ya obsoleta teoría miasmática humoral, que provocó la necesaria higienización de pueblos y ciudades, o mediante los sorprendentes puntos de vista sobre los semina y los corpuscula que Lucrecio y Varrón ofrecieron sobre la propagación de estas enfermedades, muy similares a la teoría viro-bacteriana de Louis Pasteur que, por otro lado, constituye la base de la actual forma de acometer las enfermedades infecciosas, mediante vacunas y fármacos que atacan a virus y bacterias, "descendientes" de los "clásicos” semina y corpuscula.

Las epidemias y pandemias de la antigua Grecia y Roma responden a la misma sintomatología y comportamiento de los virus actuales. Cuando no hay vacunas, es necesario aprender de los clásicos cómo actuar y sentirnos acompañados por su sabiduría. 
Se prohíbe su reproducción total o parcial por cualquier medio, incluido electrónico, sin permiso previo y por escrito de los editores. 